\title{
PRINCIPLES AND EXAMPLES OF DESIGN OF REHABILITATION CENTERS IN RUSSIA AND ABROAD
}

\author{
Marina Zvyagintseva, Julia Skripkina*, Natalia Fedorchenko \\ Southwest State University, Kursk, Russian Federation
}

This article examines and analyzes the design features of rehabilitation and medical centers in Russia and Europe. The principles of formation of constructive, functional and aesthetic, as well as economic, social and environmental aspects of the development of projects of rehabilitation centers are revealed. The interrelation and influence of architecture on the process of treatment of patients during rehabilitation is shown. On the basis of foreign and Russian experience, conclusions are drawn about the design and design of rehabilitation centers, which take into account the developed project of the health and rehabilitation center.

Key words: rehabilitation, comfortable environment, medical institution, architectural solution

\section{INTRODUCTION}

Rehabilitation treatment as an independent direction appeared in Russia not so long ago, especially acute need for it was found in Russia after the reforms of 1991 in connection with the critical decline in the level of population health. Subsequently, this need was further intensified, which was caused by the beginning of the demographic crisis, the lack of forces and means to ensure timely assistance in the necessary volume and quality of medical care for the sick and disabled.

In the process of development of restorative medicine the purview of this new direction was expanded from the restoration of health in healthy person to restore critical functions of the organism at all stages of prevention and rehabilitation [1].

Both in our country and abroad, the experience of creating such health and rehabilitation centers, combining the maintenance of the General health of the population and the treatment of patients who are shown a course of medical rehabilitation, has been successful. This integration is effective both from a medical and from an economic point of view.

The comfortable environment should satisfy aesthetic, psychophysiological, ergonomic needs and features of the person [2]. It includes the following components: spatial comfort, visual comfort, functional comfort, which will provide psychological and physiological comfort for a person.

An integrated approach involves the preparation of alternatives that take into account all aspects of the problem - economic, social and environmental [3].

\section{MATERIALS AND METHODS FOR SOLVING THE PROBLEM}

Consider the basic principles that help you choose the right planning decisions:

1. the principle of an individual dwelling house is the most common type of rehabilitation centers. The main centers for dependent persons existing in Russia are built on this principle. In a country house, rehabilitation provides the necessary comfortable environment, usually small narrow-profile centers [3];

2. the principle of open composition is more suitable for a large or multi-profile narrow center. Open plans "let in" the external environment inside the center, keeping its clear boundaries, while the closed composition technique is used in the urban environment to isolate the institution from the unfavorable background, thus, a closed complex associated with the natural environment is obtained.

3. the principle of rehabilitation village is a planning that goes beyond one volume and takes the features of urban planning element. A rehabilitation village can be a collection of different centers, united by a common infrastructure on one site. On the basis of this option, a settlement is formed with a developed rehabilitation environment integrated into the natural environment. Rehabilitation settlement may include multi-complexes, centers in the form of a country house, sanatoriums, recreation, sports, entertainment facilities. They provide a comfortable stay of the patient on the territory of the rehabilitation village.

In Europe, much attention is paid to the architecture of public buildings: kindergartens, schools, universities, libraries and hospitals. Almost all new buildings are built using environmental technologies and have a modern, concise design. Especially carefully thought out projects of medical institutions. For restorative treatment, it is necessary to take into account not only the quality of medical services, but also the aesthetics and convenience of the premises in which the treatment takes place.

One of the most unusual buildings of medical institutions-the building for the treatment of youth at the psychiatric center in Zaragoza (Spain), erected in 2011 (Fig. 1, a). The building is a long one-story red building with a series of gable roofs, pointed at different angles and similar to a string of electrocardiograms. Both walls and roof are 
covered with zinc plates; uniformity is interrupted only by identical square Windows without frames. Inside the building there are ten single and eight double rooms with bathrooms. There are also two common living rooms and a dining room. The interior is decorated in bright colors. With the help of an underground tunnel, this building is adjacent to the neuropsychiatric center "Nuestra Senora del Carmen".

Also worth noting is the project of the new North Zealand hospital in Hillerod in Denmark, which was proposed by the Studio C. F. Møller Architects (Fig. 1, b). The citizens of North Zealand in 2020 will be able to have a new and modern hospital in green surroundings near the town of Hilleredd for 310,000 residents of the area, with a budget of up to DKK 3.8 billion. The idea of the new North Zealand hospital was to create a landmark for nearby Frederiksborg castle. This hospital, where architecture and nature merge and form a safe environment for patients, is very functional and attractive to all citizens in the area. The hospital grows out of forests and constantly brings people closer to nature both inside and outside, creating a healing architecture focused on the patient. The architectural and acoustic expression of the structure is also based on an organic, soft and humane design.

It is generally believed that the interior of a hospital should look like a white, completely sterile and cold room, but
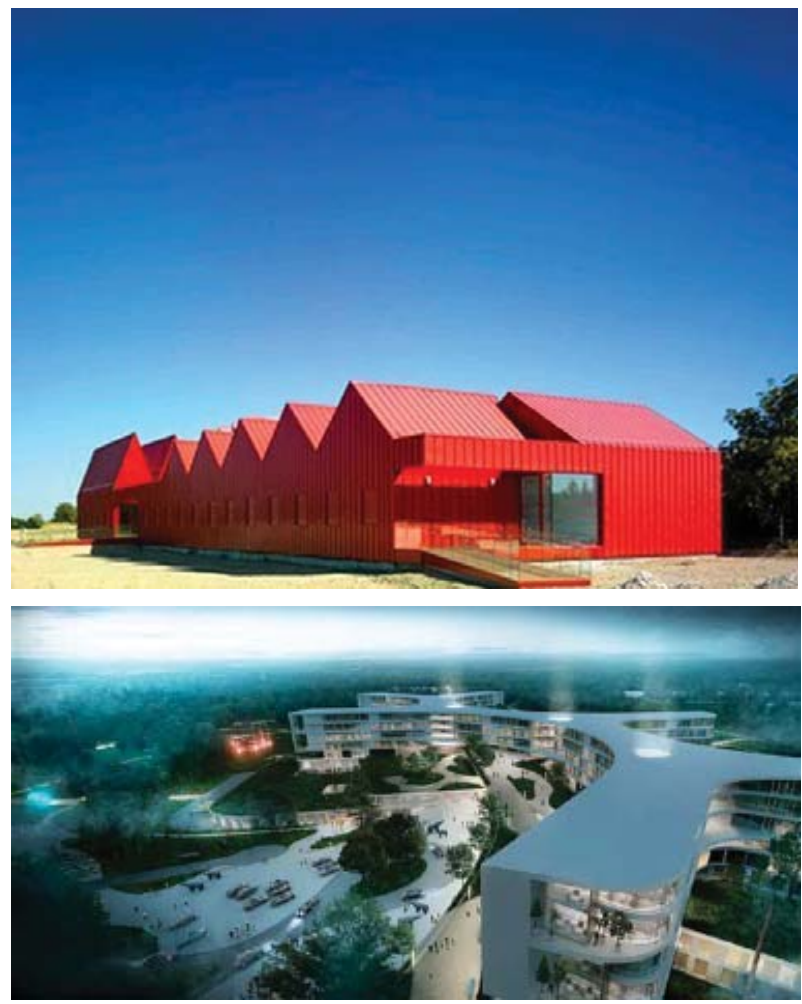

(a)

Figure 1: European medical institutions:

a) the youth treatment unit at the psychiatric centre in Zaragoza (Spain)

b) the draft of the New North Zealand hospital in Hillerød (Denmark)
Maggie's cancer Centre in Manchester breaks this stereotype (Fig. 2, a). The design of the centre in Manchester is designed in such a way that each of its components, including the garden, radiated a comfortable home atmosphere. The design of the center is replete with natural accents. Natural light, greenery and garden are among them. The linear configuration is broken by elements of landscape design, and along the entire Western facade extends a wide veranda, which is protected from precipitation by a large canopy. Patients of the center take part in the beautification of the landscape, charging with the healing energy of nature in the open air.

Rehabilitation center Veilige Veste in Leeuwarden, the Netherlands, Is also very interesting (Fig. 2, b). The name of the project "Veilige Veste" is translated as "safe fortress", it very accurately describes the essence of the project. It is a new centre for the rehabilitation of girls who have become victims of trafficking. The project of the center was developed by architects from the Dutch Studio KAW Architecten. The incredible efforts of the architects were aimed at creating a sense of security and peace in the residents of the house. The center looks like a new building, but in fact, it is a completely rebuilt police station, built in the 70s. The structure is faced with relief white square slabs. Since the facade has a reflective property, it seems that it is in a dynamic state. The first floor of 1600 square meters is occupied by treatment

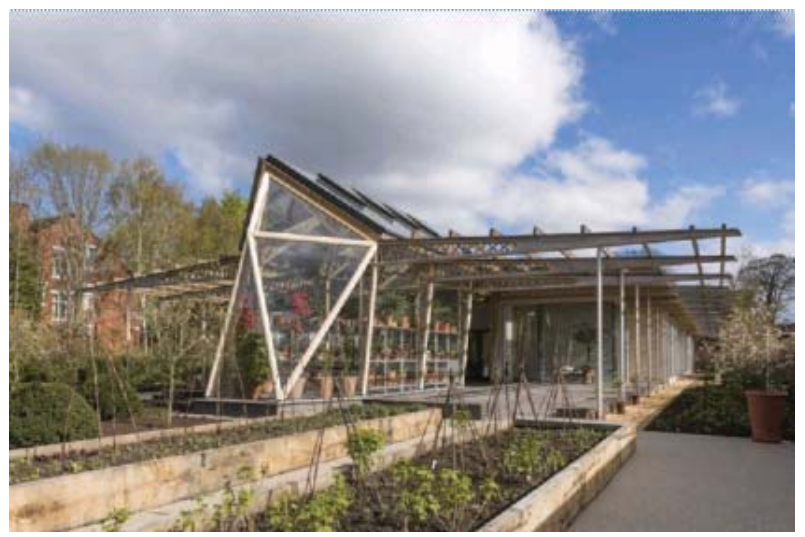

(a)

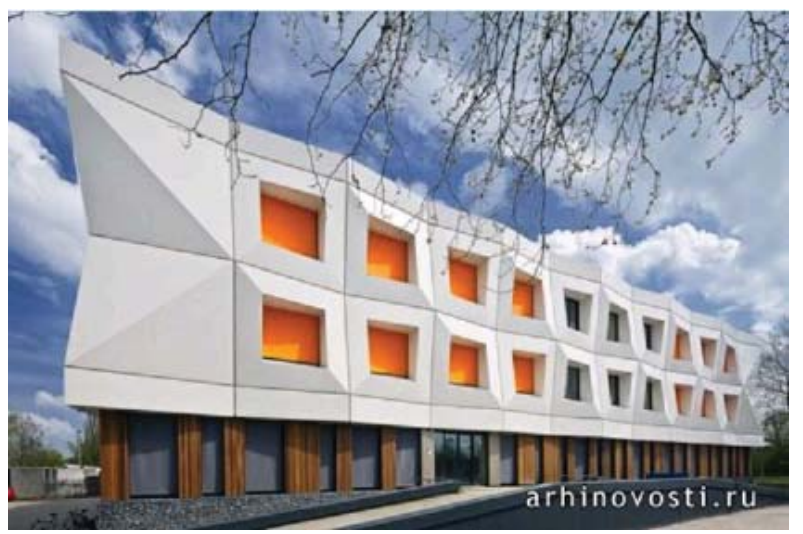

(b)

Figure 2: European medical centres:

a) Maggie's cancer Centre in Manchester

b) Rehabilitation centre Veilige Veste in Leeuwarden,

(Netherlands) 
rooms, offices and meeting rooms. On the second and third floors there are living rooms for 48 girls. On the third floor there is also a cozy garden, where the girls, despite the fact that they are on the street, feel safe. The Veilige Veste project is the first building in the Netherlands to be rebuilt to the standards of a "passive house", or energy-saving. This house consumes incredibly little energy, thanks in part to good thermal insulation.

Fortunately, the quality of medical facilities in Russia has improved recently. Some of them, in their organization and design are not inferior to foreign [4].

The complex of the Center of pediatric Hematology, Oncology and immunology consists of a polyclinic, medical buildings and a hotel block under the conditional name "Tree of life "(Fig. 3, a). At the same time, the Center can serve 400 children, 250-300 inpatient beds are planned. The single complex includes various functional blocks: medical, educational and polyclinic, research, as well as a boarding house for children undergoing medical rehabilitation. It is a kind of residential building with apartments-blocks consisting of three living rooms for mother and child [3].

The overall solution of the complex is a few bright volumes, similar to multi-colored cubes with colored inserts on the facades. The Facade solution uses bright, contrasting colors - orange, purple, turquoise, yellow, red.

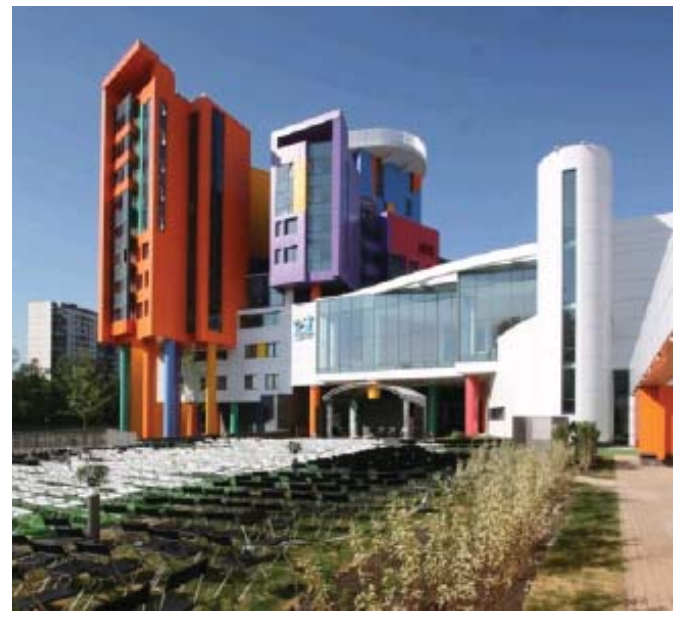

(a)

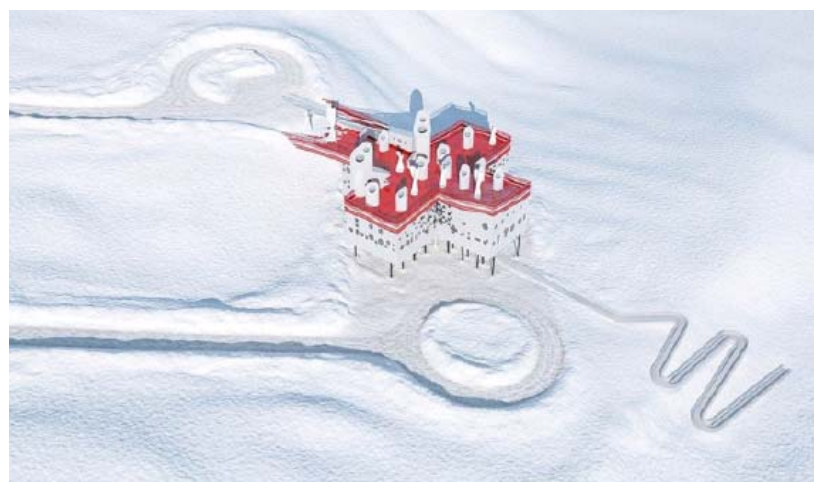

(b)

Figure 3: Russian medical institutions:

a) Complex of the Center of pediatric Hematology, Oncology and immunology in Moscow;

b) the Red Cross Rehabilitation center
The tent block is a high-rise hotel towers raised above the ground on columns, almost completely colored as an accent, and the facades of medical buildings are more laconic, white or black, with bright inserts.

The Red Cross rehabilitation center is a futuristic building and looks like a bunker prepared in case of bombing and nuclear winter (Figure 3, b). The hospital decided to strengthen from all sides because of the special location-construction is planned in the village of Egvenikot in the far East of Russia. This village is located in the Chukotka Autonomous Okrug on the Bering sea. The building can be approached by wild animals, so to protect patients, the architectural Bureau Norm Architects came up with the concept of a high-tech fortified yaranga - the national home of local peoples. Due to the dome shape, the rehabilitation center really resembles a traditional house of Chukchi and Koryaks - but the internal equipment corresponds to the current trends of the centers of recovery from diseases. There are private rooms, a dining room and rooms for work and study there.

\section{RESULTS AND DISCUSSION}

On the basis of foreign and Russian experience in the design of medical facilities, a project of a health and rehabilitation center was developed (Fig. 4). The project of this center used the principle of open composition. On the plan it is a complex multi-level figure consisting of two curved at 90 degrees four-story rectangles and adjacent three-, two- and one-story forms.

The proposed color scheme is perfect for rehabilitation medical institution, as it uses natural shades of glass, wood and metal.

Exterior decoration of the building (wall fence) is carried out by covering the structure of the hinged facade in white. When designing facades, compositional techniques are used in the form of a clear allocation of the surface of the hinged facade with vertical and horizontal

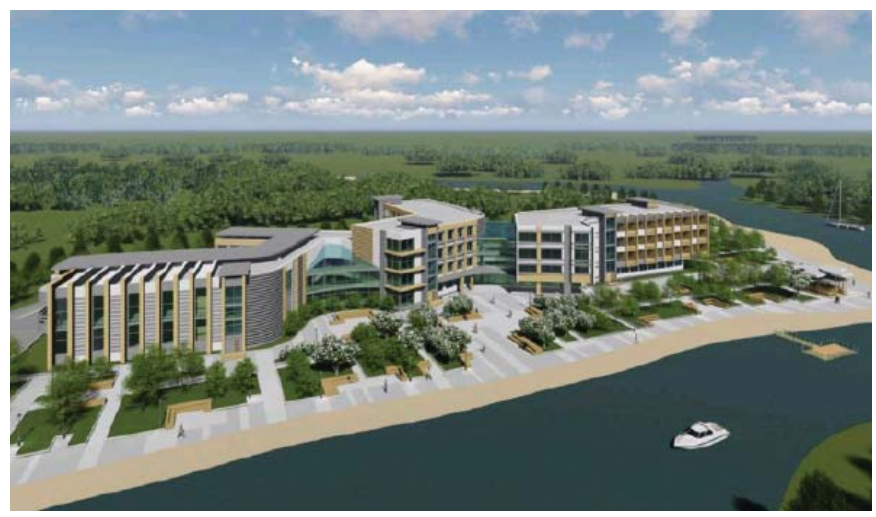

Figure 4: Health and rehabilitation center

In four-storey blocks there is a hospital, medical and diagnostic Department and administrative part. In the three- and two-storey part there is a reception and lobby block, Department of rehabilitation treatment,

Department of psychological and pedagogical treatment. 
seams and rhythmic division of the volume of the building into window openings made of plastic profile and blind wall surfaces combined into a single ornamental pattern, which gives architectural expressiveness to the facades. The total volume of the health and rehabilitation center has a patio in the recess of the form, which allows patients to relax in privacy, regardless of weather conditions: if a side wind or sultry sun, for example, patients can go to rest in the courtyard.

The entrance to the center is made in the form of a glass volume with an atrium inside. The atrium plays the role of a foyer, a common lobby and a walking area for patients undergoing treatment. The entrance is through, you can go directly to the patio. Inside the three-storey part there is a winter garden surrounded by glass walls and an atrium.

Constant visual environment with intense aggressive visual elements has a strong impact on the human psyche, so the rehabilitation of patients should be carried out in a natural environment devoid of visual discomfort [6]. Clean air, pleasant climate, favorable environment and a certain distance from residential buildings (direct transport accessibility) are also necessary for the placement of medical and preventive institutions.

When checking proposals for new development of territories for construction, an analysis of possible environmental conflicts is carried out. First of all, compliance of project proposals with legal documents on nature, landscapes and water resources protection is monitored, then the degree of intervention in nature and landscape is assessed, measures to protect temporary impacts are planned [7].

\section{CONCLUSIONS}

Healthcare facilities today differ from the previous ones mainly by a flexible approach to the placement of medical technologies, new structural and spatial planning solutions, the use of modern materials and construction technologies, as well as by free planning, which takes into account the specific urban situation.

When designing this rehabilitation center, more attention is paid to creating a comfortable environment that contributes to the effective work of medical staff and the speedy recovery of patients. It is for this purpose that the boring typical corridor layout is rejected, so that patients and staff feel more comfortable.

In addition, the architectural design of this structure includes a comprehensive solution of compliance with structural, functional and aesthetic requirements to the object, as well as economic, social, environmental, sanitary, engineering and technical aspects developed in the architectural part of the documentation for the project and implemented during construction.

\section{REFERENCES}

1. Razumov A.N. New projects of rehabilitation medicine development [Network resource]. http:// vosmed.ru/clauses/new_vosmed_razumov.html

2. Pilipenko O., Bakaeva N., Gordon V., Natarova A. 2017. Quantitative assessment of environmental safety of real estate objects on the basis of the concept of green construction. Scientific and technical journal. №. 4: 45-59.

3. Pozdnyakov, L. A., Pozdnyakova, V. E., Zvjagintseva, M. M., \& Barsova, Y. O. [2018]. System analysis as the general methodological basis of town-planning designing. Journal of Applied Engineering Science, 16(1), 79-82.

4. Gaiduk A.R. 2015. Architectural principles of volume-planning organization of children's clinical and rehabilitation cancer centers: thesis. Nizhny Novgorod, 216 pp.

5. Fedorchenko N.O. 2019. Principles of architecture and design in the rehabilitation center. Architectonics of regional culture. Kursk. Pp. 58-61.

6. Pozdnyakov A.L. 2016. Ecological problems of cities and settlements in Russia and abroad. Series Technics and technologies. №. 3: 109-115.

7. Pozdnyakov, A. [2017]. Ecological and economic aspects of planning of urban development. Journal of Applied Engineering Science, 15(4), 418-421.
Paper submitted: 13.08.2019.

Paper accepted: 15.11.2019.

This is an open access article distributed under the CC $B Y-N C-N D 4.0$ terms and conditions. 